\title{
El Word of Mouth: construcción de un modelo del proceso a partir de la revisión de la literatura
}

Word of Mouth: Construction of a Process Model Based on a Review of the Literature

Joanne Robinson

Graduada Ciencias Empresariales

Internacionales (E4)

jo.robinson89@btinternet.com

Carmen Valor

Universidad Pontificia Comillas

cvalor@upcomillas.es
Robinson, J. y Valor, C. (2013)

El Word of Mouth: construcción de un modelo del proceso a partir de la revisión de la literatura. Revista Internacional de Investigación en Comunicación aDResearch ESIC. № 8 Vol 8. Segundo semestre, julio-diciembre 2013 · Págs. 8 a 25 DOI: 10.7263/ADRESIC.008.001 
RESUMEN

\section{Clasificación JEL:}

M37, M14

Palabras clave:

boca a boca,

comportamiento

del consumidor,

influencia social,

valencia del mensa-

je, intensidad de la

relación,

credibilidad, interac-

ciones online.

\section{ABSTRACT}

\section{JEL Classification:}

\section{M37, M14}

Key words:

word of mouth,

consumer behaviour, social influence, message valence, relationship tie strength, credibility of source, online interactions.
El boca-oreja o WOM forma parte de las interacciones del día a día de los consumidores. Sin embargo, su influencia es clave, ya que las fuentes personales son las primeras en importancia para los consumidores. Este trabajo realiza una revisión de la literatura sobre el WOM y analiza los resultados de los estudios realizados. Se creó una base de artículos encontrados en EBSCO Host, Academic Source Complete, Business Source Complete, E-Journals, Jstor y Web of Science, sin limitar cronológicamente (1960-2011). Se concluye que los estudios encontrados se han dedicado a analizar la influencia de una, a lo sumo dos, variables a la vez. Se termina, pues, proponiendo un modelo gráfico y verbal (en forma de proposiciones) del proceso de WOM, donde se identifican las variables clave (motivación, credibilidad, relación entre emisor y receptor y mensaje) y se identifican las relaciones entre ellas, cosa que no habían realizado anteriores trabajos. Este modelo deberá ser falsado en futuros estudios.

Word of mouth (WOM) communication is a major part of day to day interactions. However, its influence is deemed key by marketers, since personal comments are considered the most influential by consumers. This paper conducts a literature review on WOM and analyses the findings of previous studies. A database was built with papers found in EBSCO Host, Academic Source Complete, Business Source Complete, E-Journals, Jstor and Web of Science, in the period 1960-2011. We conclude that previous papers have focused on one, two at most, variable at a time. We offer a graphic and verbal model of the WOM process (in the form of propositions), where determinant variables are isolated (i.e., motivation, credibility, sender and receiver relationship, and message) and their relationships were estimated. Previous works have failed to identify these relationships among independent variables. This model should be tested in future studies. 


\section{Introducción}

Una parte importante del comportamiento del consumidor ha tratado de identificar y conocer cómo influyen diferentes factores en la conducta de compra del consumidor. Uno de los factores que ha recibido más atención son los factores sociales: cómo la influencia de los otros puede modular la toma de decisiones del consumidor.

En este contexto de influencia social debe enmarcarse el proceso de boca-oreja o boca-boca o WOM, por sus siglas en inglés (word of mouth), o recomendaciones personales. Blackwell et al (2002: 404) lo definen como "un tipo de influencia social que se refiere a la transmisión de ideas, comentarios, opiniones e información entre dos personas". Pero no toda recomendación personal es WOM. Es importante diferenciar entre el consejo que viene de otros consumidores y el consejo que viene de los interesados comercialmente, como dependientes o vendedores, que no sería WOM (East et al, 2005; Richins, 1983). Está aclaración es importante ya que identifica la naturaleza fundamental del concepto: la fuente no tiene un interés comercial y se percibe como independiente de las actividades de marketing de la empresa.

Esta influencia ha existido siempre y siempre se ha considerado que es un factor importante en la toma de decisiones. Según Godes y Mayzlin (2004) el WOM es uno de los recursos de información más influyentes en cualquier sociedad. Igualmente, Peters (1987, citado por Mason, 2008: 207) afirmaba que "un 10\% del mundo influye en el otro 90\%”. En comparación con otros medios de comunicación, se ha encontrado que el WOM puede ser más dominante que la información escrita. Katz y Lazarsfeld (1955), los investigadores que quizá iniciaron el estudio de la influencia social en la toma de decisiones, encontraron que para conseguir que el consumidor cambie de marca, el WOM era "7 veces más efectivo que los medios de comunicación impresos, 2 veces más efectivo que los medios de emisión (televisión y radio) y 4 veces más efectivo que los vendedores" (citado por Hoyer y MacInnis, 2004: 411).

Aunque el WOM es, evidentemente, un concepto poco novedoso, hoy su influencia se ha amplificado por el impacto de las nuevas tecnologías y, especialmente Internet, que facilita la transmisión del WOM a mayor número de personas, más rápidamente y con mayor facilidad. A este WOM realizado a través de Internet se le denomina eWOM (Bickart y Schindler, 2001), que se traduciría por boca-a-boca electrónico. En el eWOM la conversación ocurre en foros, salas de chat, blogs, redes sociales, grupos de discusión, tableros online y páginas web de opiniones. Hennig-Thurau et al (2004: 39) definen el eWOM como "cualquier declaración positiva o negativa realizada por consumidores potenciales, actuales o antiguos sobre un producto o una empresa, que está disponible para una multitud de personas e instituciones a través de Internet". No obstante, se debe tener en cuenta que hay conversaciones online que no son públicas, sino privadas, por ejemplo, vía email, y también se consideran eWOM.

Parece que la recomendación online es igual de efectiva que la recomendación offline, especialmente comparada con el no WOM. Nielsen (2009a) en una encuesta online con una muestra de 25.000 consumidores de más de 50 mercados, comparó la confianza entre 16 diferentes canales de información. El estudio concluyó que, en comparación con otras fuentes tales como televisión, revistas y publicidad exterior, la recomendación personal (el WOM) es la forma 
de recibir información en la que más confían los consumidores, especialmente, la recomendación obtenida de personas cercanas al sujeto: 9 de cada 10 personas confían en las recomendaciones personales y 7 de cada 10 en las opiniones de otros consumidores en Internet. Otra encuesta de la AIMC (2010) encontró que aproximadamente 7 de cada 10 internautas habían consultado opiniones en Internet; la mayoría le concedía una gran confianza.

Pese a la importancia que tienen ambas formas de recomendación (en adelante, nos referiremos tanto a la offline como a la online con la expresión WOM) lo cierto es que no hay todavía un modelo claro que explique el proceso por el que se produce esta influencia ni hay una identificación clara de las variables mediadoras en el mismo. Por eso, este trabajo pretende, a partir de la revisión de estudios anteriores, desarrollar un modelo del proceso de WOM, identificando las variables clave. Se trata de reunir de una forma sistemática un conocimiento que actualmente está disperso en diferentes estudios.

Para realizar esta revisión de la literatura se han empleado los estudios recopilados en bases de datos científicas, en concreto, EBSCO Host, Academic Source Complete, Business Source Complete, E-Journals, Jstor y Web of Science on Web of Knowledge. No se ha limitado cronológicamente la búsqueda, abarcando las referencias encontradas el periodo 1960-2011. La búsqueda ha permitido recuperar 55 estudios, de los que 40 han sido analizados en profundidad, ya que se centraban en identificar variables mediadoras clave en el proceso de WOM. De estos artículos, la mitad fueron publicados en la primera década del siglo xxi. En total, desde 2000 fueron publicados el 65\% de los artículos analizados. Esto evidencia que el desarrollo de las tecnologías de comunicación, especialmente Internet, ha llevado a dar todavía más importancia a la recomendación personal.

Tras una categorización de las variables analizadas, en este artículo se describen las conclusiones más relevantes. Además, se añaden comentarios sobre las metodologías utilizadas y sobre la definición de la variable dependiente. Después, se proponen proposiciones para guiar futuros estudios y se resumen estas proposiciones en forma de modelos gráficos. Finalmente, se ofrecen unas conclusiones, con una propuesta de agenda de investigación.

\section{Consideraciones Iniciales: meto- dologías para el estudio del WOM}

Varias son las metodologías utilizadas para el estudio del WOM. Los grandes institutos de investigación suelen recurrir a encuestas. (AIMC, 2010; Nielsen, 2009; Trnd 2010), ya que permiten obtener una muestra amplia y profunda. Sin embargo, investigadores localizados en universidades o centros de investigación no comerciales suelen recurrir a entrevistas en profundidad. Esta metodología permite que el investigador pueda profundizar en el fenómeno objeto de estudio, especialmente, motivaciones (Czepial, 1974; Martilla, 1971; Mason, 2008; Richins, 1983).

No obstante, los dos métodos tienen desventajas con respecto a la fiabilidad de la información en la respuesta del encuestado, debido al énfasis que se pone en el recuerdo. El entrevistado debe hacer memoria de experiencias pasadas, en las que emitió o recibió una recomendación personal, y ser capaz de reconocer los factores que llevaron a ello y sus consecuencias. No cabe esperar que la memoria del entrevistado sea sin tacha. Si la situación de WOM ocurrió hace mucho tiempo es probable que el entrevistado no 
recuerde todos los detalles ni las influencias ni los efectos que podrían haber ocurrido. Asimismo, podría responder a las preguntas según lo que crea que el entrevistador quiere escuchar, para intentar satisfacer al entrevistador sin contar la situación real. Por todo ello, algunos autores señalan que el WOM "no ha sido investigado exhaustivamente, debido a la pobre calidad que existe para medir el concepto" (East et al, 2005: 146).

Otro método usado por investigadores es el experimento controlado (Gupta y Harris, 2010; Herr et al, 1991; Laczniak et al, 2001). En esta situación se pueden controlar las variables objeto de análisis, por lo que se puede afirmar que la validez de los resultados es mayor. Sin embargo, el problema de esta metodología es la dificultad para generalizar a otras situaciones y al mundo real. El WOM generado en condiciones de laboratorio, bajo control de los investigadores, no es necesariamente igual al que ocurriría en un contexto real, donde hay más factores e influencias que pueden intervenir y afectar al resultado. Así, otros han optado por observar la conducta de los consumidores en situaciones casi reales. Por ejemplo, Reingen et al (1984) comparó a mujeres que viven en la misma casa, con mujeres que no viven juntas, para analizar la influencia de la fortaleza del vínculo.

Otro problema metodológico en el estudio del WOM es la elección del producto o servicio. No está claro que se puedan generalizar resultados obtenidos sobre WOM en una categoría a cualquier categoría de producto. Dado que, como se verá luego, una de las razones para participar en WOM es reducir la incertidumbre, cabe esperar que la influencia del WOM será mayor en productos de alta implicación.
Por otro lado, el desarrollo de Internet pone al alcance nuevas herramientas para la medición de WOM. En primer lugar, se ha ampliado el alcance de las encuestas, dado que se pueden difundir online con más facilidad y rapidez, ahorrando costes y tiempo de investigación. En segundo lugar, con la llegada de eWOM, se han tenido que desarrollar distintas maneras de medir las conversaciones en comunidades online, foros y tableros de discusión, dado que el eWOM ha hecho públicas lo que antes eran conversaciones privadas. Por eso, parece más fácil medir la influencia del eWOM que del WOM, porque aquel ocurre públicamente. Esta facilidad para el estudio del WOM online podría explicar que el mayor volumen de artículos sobre el particular se haya producido en las últimas dos décadas.

Algunas de las herramientas introducidas para observar las conversaciones tienen nombres genéricos como: buzz monitoring, buzz metrics, reputación online, entre otros. Fisher (2008: 10) explica que el buzz monitoring es "una manera de medir la reputación de una marca según los comentarios realizados por consumidores online sobre la marca en foros, blogs y salas de chat". Algunas empresas han desarrollado sus propias versiones de las herramientas bajo el nombre de la empresa. Nielsen (2009b) desarrolló su Nielsen BuzzMetrics para "captar y analizar el contenido y los mensajes de más de 100 millones de blogs, grupos de usuarios y redes sociales por todo el mundo". Es un programa de la empresa que se ofrece para poder monitorizar y analizar lo que los consumidores están diciendo online sobre su marca u organización. Se han creado, incluso, asociaciones para impulsar la investigación sobre el fenómeno (véase, por ejemplo, la Word of Mouth Marketing Association o WOMMA). 
No obstante, según Dellarocas et al (2004) en algunos casos la metodología para analizar la información recogida por el eWOM todavía no ha sido establecida ni desarrollada en profundidad. Dice que "aunque las empresas pueden recoger grandes cantidades de información por comunidades online, todavía no está claro cómo lo deben analizar" (Dellarocas et al, 2004: 2).

\section{La variable dependiente: ¿Qué se entiende por eficacia en WOM?}

Es importante destacar que cuando se afirma que el WOM es una herramienta poderosa no se está aclarando mucho sobre sus posibilidades, por eso, se ha querido iniciar el modelo explicando la variable última: la de resultado. Lo cierto es que no hay acuerdo en los trabajos sobre qué se debe entender por eficacia en el estudio del WOM. Cuando un estudio trata de determinar si tal o cual variable hará el WOM más eficaz, no define de forma rigurosa qué se entiende por WOM eficaz. Así, encontramos que se han utilizado como variables resultado o variable dependientes diferentes conductas, por lo que, en puridad, no todos los estudios han estudiado lo mismo, pese a que coincidan en el título.

Básicamente los estudios anteriores han definido la variable resultado como una de estas cuatro formas: notoriedad y conocimiento (por ejemplo, Duhan et al, 2007; Herr et al, 1991; Liu, 2006), cambio de actitud (por ejemplo, Arndt, 1967; Brown y Beltramini, 1989; Laczniak et al, 2001; Liu, 2006), compra del bien/marca (por ejemplo, East et al, 2005; Godes y Mayzlin, 2004; Gupta y Harris, 2010) o dispersión del mensaje.

Lo cierto es que la mayoría de la investigación anterior no ha analizado realmente la influencia del WOM en la compra, sino en otras variables del proceso de compra. Cuando se ha estudiado la influencia en la conducta, se ha tendido a elegir compras simples, muy influenciables por la recomendación personal y no por otros factores (elección de películas en televisión o cine) (Chintagunta et al, 2010; Duan et al, 2008; Godes y Mayzlin, 2004; Liu, 2006).

Además, lo más frecuente es tomar como variable resultado la dispersión del mensaje, esto es, considerar que el WOM ha sido eficaz cuando ha generado más recomendaciones personales. De hecho, la inmensa mayoría de estudios emplean esta variable resultado en todo caso. Cabe esperar que si una recomendación es valorada se pasará a más gente, generando nuevo WOM.

En conclusión, la eficacia del WOM parece definirse como aceptación del mensaje. Si el mensaje es aceptado se compartirá (dispersión del mensaje). No está claro en la literatura cómo se producirá su influencia en la decisión de compra. Un mensaje puede ser difundido y no generar cambios en la decisión de compra, o no generar un cambio de actitud sostenido. Aclarar cómo el WOM influye en la decisión de compra es uno de los huecos más evidentes de la investigación sobre WOM, como se explicará más tarde. Las conclusiones sobre la definición de resultado en WOM se presentan en el gráfico siguiente. (Cuadro 1 pág. 14)

\section{Variables independientes 0 determinantes del WOM}

Varios factores explican que se produzca el WOM y que éste tenga mayor o menor efecto. En la literatura, se ha prestado atención a algunos de estos: las motivaciones, la relación entre el emisor y receptor, la credibilidad del emisor y la valencia del mensaje. A continuación se explica cada uno de ellos. 


\section{Cuadro 1 - Conclusiones de la variable dependiente}

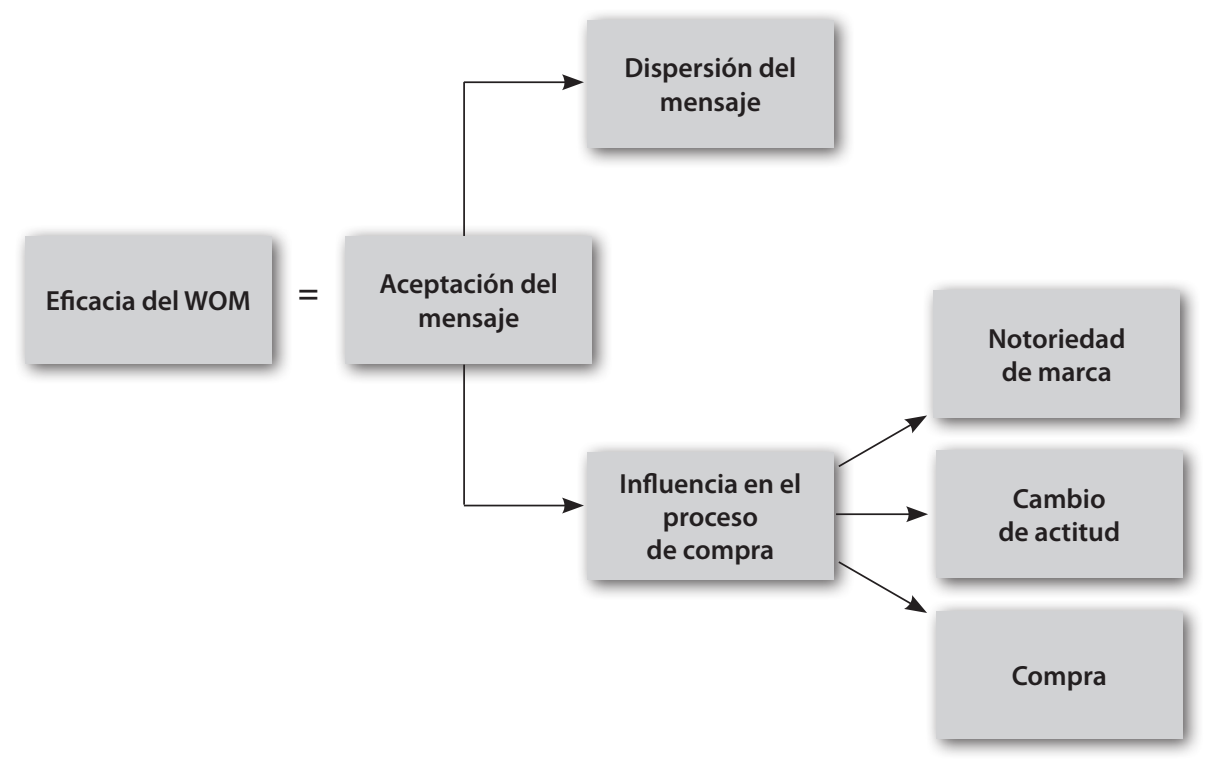

\subsection{Motivación como variable determi- nante del WOM}

Se entiende por motivación la razón que lleva tanto a emisor como receptor a difundir/buscar una recomendación personal. En cuanto al emisor, el estudio más antiguo sobre las razones por las que un consumidor compartía recomendaciones positivas con otros consumidores lo realizo Dichter (1966), mediante entrevistas en profundidad a 255 consumidores de 24 localidades de los Estados Unidos. Dichter clasificó las motivaciones para hacer WOM en cuatro tipos: para aliviar la tensión o emoción por el uso del producto, para recibir atención y buscar apoyo de otros, para ayudar a otros o para compartir la exposición a algo.

Estudios posteriores han analizado las motivaciones para hacer WOM positivo y negativo.
Así, Sundaram et al (1998), utilizando la misma metodología que Dichter, confirmaron los resultados anteriores. En el caso del WOM positivo se añade otro motivo: el deseo de ayudar a la empresa. De hecho, son los consumidores particularmente satisfechos con su experiencia de consumo los que más probablemente entablen una conducta de ayuda, a través de mensajes positivos sobre la empresa. Encontraron también una asociación entre la experiencia de consumo y el motivo para hacer WOM: si la experiencia ha sido mala, el motivo está más ligado a la venganza; si ha sido buena, compartir o ayudar.

Estos trabajos fueron revisados por HennigThurau et al (2004), quienes estudiaron la motivación para participar en el eWOM, empleando una metodología ligeramente diferente. A una muestra de 2.063 participantes, seleccionados 
por su interacción en comentarios online, se le pedía que indicara su acuerdo o desacuerdo con el motivo propuesto. Encontraron cuatro factores principales para explicar las motivaciones de los generadores de WOM: deseo de interacción social, búsqueda de un incentivo económico, interés y preocupación por otros consumidores y para mejorar y elevar la autoestima.

Vista la motivación del generador de WOM, analicemos ahora la motivación del receptor de WOM. East et al (2005) encontraron, a través de encuestas de distintas categorías de productos, que un 49\% de las recomendaciones expresadas lo fueron a resultas de una petición. Así, hay un cierto equilibrio entre las recomendaciones proactivas (las generadas por el emisor motu propio) y las reactivas (las generadas en respuesta a una consulta o pregunta). Pero la diferencia entre la forma de generación del WOM no es baladí, ya que el WOM reactivo tiene un impacto en la elección de la marca mucho mayor (de 1,5 a 2 veces más grande) (East et al, 2005), porque la motivación del receptor para usarlo en su proceso de toma de decisiones es mayor.

Otros autores han estudiado otras variables relacionadas con la motivación del receptor. Por ejemplo, Duhan et al (1997) concluyen que la motivación fundamental del receptor para usar las recomendaciones personales es simplificar la fase de procesamiento de información, reduciendo el volumen de información que deben procesar y minimizando la incertidumbre o riesgo percibido. Igualmente, Schindler y Bickart (2005), enfatizan que el receptor busca simplificar la búsqueda y procesamiento de información al participar en WOM. Otros motivos son el entretenimiento o la búsqueda de apoyo social (Blackwell et al, 2002; Van Hoye y Lievens, 2007)
En conclusión, generadores y receptores de WOM tienen razones diferentes para enviar y recibir recomendaciones personales. Así, mientras el emisor está más orientado por beneficios psicológicos, sea de mejora de su autoestima, sea de mejora de la estima en el grupo, el receptor busca beneficios funcionales, asociados a la reducción de incertidumbre y la simplificación del procesamiento de información, tal como se resume en el cuadro siguiente.

Además, otras dos variables parecen relevantes en relación a la motivación:

- La forma de generarse el WOM: si es reactivo influye más en la elección de marca;

- El grado de (in)satisfacción del emisor: a mayor (in)satisfacción mayor probabilidad de generar WOM (mayor dispersión del mensaje) (esta variable se explora en mayor detalle en el epígrafe sobre valencia del mensaje).

Finalmente, cabe añadir que la motivación del emisor es una variable moderadora de la eficacia del WOM porque, como se explicará después, los receptores juzgan la motivación del emisor y sobre esta infieren la credibilidad del emisor como fuente. (cuadro 2 pág. 16)

\subsection{Relación entre emisor y receptor}

La fortaleza del vínculo entre emisor y receptor de WOM (Brown et al, 2007) es un factor clave para explicar la eficacia del mismo. Granovetter (1973: 1361) entiende que la fortaleza de un vínculo depende del "tiempo, intensidad emocional, intimidad y reciprocidad que lo caracteriza”. Así, familia y amigos se consideran vínculos fuertes, mientras que conocidos se consideran vínculos débiles.

Varios trabajos han encontrado que la fortaleza del vínculo afecta tanto a la cantidad de información generada (Brown y Reingen, 1987; 


\section{Cuadro 2. Resumen de la investigación sobre motivos de emisor-receptor de WOM}

\begin{tabular}{|c|c|c|}
\hline & Motivos & Fuentes \\
\hline \multirow[t]{2}{*}{ Emisor } & $\begin{array}{l}\text { Aliviar tensión o emoción del uso del producto } \\
\text { Ayudar otros (altruista) } \\
\text { Recibir atención y apoyo } \\
\text { Compartir experiencia } \\
\text { Sentimiento de poder y de prestigio por influir en los comportamientos } \\
\text { de los demás } \\
\text { Mejor posición en el grupo } \\
\text { Menores dudas sobre el comportamiento propio } \\
\text { Proteger y defender su interés } \\
\text { Aumentar su credibilidad } \\
\text { Mayor atención y estatus } \\
\text { Incremento en el número de individuos con conductas similares } \\
\text { Mayor cohesión en el grupo } \\
\text { Mejorar y elevar autoestima } \\
\text { Interacción social }\end{array}$ & $\begin{array}{l}\text { Blackwell et al (2002), } \\
\text { Dichter (1966), } \\
\text { Hennig-Thurau et al (2004) y } \\
\text { Sundaram et al (1998) }\end{array}$ \\
\hline & Motivos & Fuentes \\
\hline Receptor & $\begin{array}{l}\text { Reducción del riesgo de un comportamiento nuevo } \\
\text { Aumento de la confianza de la elección } \\
\text { Más información sobre opiniones } \\
\text { Más información fiable o creíble } \\
\text { Menos tiempo dedicado a la búsqueda } \\
\text { Consejo de cómo se debe actuar } \\
\text { Entendimiento } \\
\text { Fuente de información } \\
\text { Incremento en la probabilidad de aceptación de un grupo o individuo } \\
\text { Mejor relación con otros individuos } \\
\text { Generar apoyo por la compra } \\
\text { Interacción social } \\
\text { Entretenimiento }\end{array}$ & $\begin{array}{l}\text { Blackwell et al (2002), } \\
\text { Duhan et al (1997), East et al } \\
\text { (2005), } \\
\text { Laczniak et al, (2001), } \\
\text { Schindler y Bickart (2005) y } \\
\text { Van Hoye y Lievens (2007) }\end{array}$ \\
\hline
\end{tabular}

Trnd,2010) como a la velocidad a la que se difunde (Godes y Mayzlin, 2004). Igualmente, el vínculo afecta también al receptor, bien en su proceso de decisión de compra (Bansal y Voyer, 2000; Sweeney et al, 2008), bien en la probabilidad de difusión del mensaje (Brown y Reingen, 1987). Con todo, sigue habiendo WOM cuando existen vínculos débiles, pero la intensidad y volumen disminuyen (Czepial, 1974; Granvotter, 1973; Smith et al, 2007).

La relación con los otros puede ser tan influyente que sea más determinante incluso que la propia opinión. Por ejemplo, en un estudio sobre compra de muebles, se encontró que las previsiones de consumidores sobre cuánto le gustaría el mueble a su amigo fue un mejor pronóstico de su compra que las propias evaluaciones (Myers y Robertson, 1972). Cuando esta influencia es tan fuerte se habla de norma social: la percepción individual de lo que pensarán los demás sobre una conducta puede hacernos adoptar esa conducta, incluso cuando nuestras actitudes no son favorables a la misma (Azjen y Fishbein, 2005). 
Hay, además, una relación entre la motivación del receptor y la fortaleza del vínculo con el emisor: si el vínculo es fuerte, se busca más el WOM que si no lo es (Bansal y Voyer, 2000; Duhan et al, 1997). Igualmente, está relacionado con la motivación del emisor: cuando una persona tiene información que es significativa, tiende a compartirla con aquellos con los que mantiene vínculos fuertes (Norman y Rusell, 20006). Además, el vínculo está relacionado con la credibilidad: cuando el mensaje viene de un vínculo fuerte, se acepta más (Van Hoye y Lievens, 2007). Esta podría ser la razón última que explica que haya más volumen y velocidad en el WOM entre grupos con vínculo fuerte.

Esto ocurre igualmente en el ámbito online (Godes y Mayzlin, 2004): cuando existe un vínculo fuerte se comparte más información y más rápidamente. Sin embargo, otros estudios (por ejemplo, Brown et al, 2007) han encontrado que en las comunidades online los vínculos entre personas son menos importantes, ya que el vínculo parece establecerse con la página web.

Otra variable que podría explicar la mayor influencia que parece darse entre vínculos fuertes es la similitud entre emisor y receptor, fenómeno conocido como homophily. Cuanto mayor es la similitud en un grupo, en términos de edad, sexo, educación y estilos de vida, mayor es el vínculo y mejor el resultado del WOM (Brown et al, 2007; Brown y Reingen, 1987). Sin embargo, en el eWOM, Brown et al (2007) encontraron que los factores tradicionales para la similitud, como edad y sexo, tenían menos importancia que los intereses compartidos. Por ejemplo, un 90\% de los encuestados habló de la congruencia entre sus propios intereses y el contenido de la página web, como factor relevante para influir en su decisión de compra. Así, aunque la similitud sigue siendo una variable relevante los determinantes de esta similitud pueden variar según el medio que se utilice para producir el WOM.

Finalmente, algunos trabajos han examinado la influencia de otras variables. Así, Lam y Mizerski (2005) analizaron la influencia del locus de control en el individuo en la probabilidad de compartir información con grupos con los que tenía vínculo débil o fuerte. Concluyeron que los individuos con alto locus de control interno era más probable que participara en el WOM con grupos de vínculo débil, mientras que aquellos con locus de control externo lo hacían con grupos de vínculo fuerte.

\subsection{La credibilidad del emisor}

Hay un acuerdo general en la literatura en que la credibilidad del emisor es clave para determinar su capacidad de persuasión e influencia sobre el receptor en cualquier proceso de comunicación (Fennis y Stroebe, 2010). También en el WOM, la credibilidad aparece como una de las variables clave para que haya influencia en la decisión de compra, tal como confirman varios estudios (Brown et al, 2007; Schiffman y Kanuck, 2005; Sternthal et al, 1978; Sweeney et al, 2008; Xie et al, 2011). Precisamente, es la credibilidad lo que diferencia el WOM de otras recomendaciones personales, como las obtenidas de vendedores o prescriptores. Aquí, la percepción del receptor de que "no tiene nada que ganar de una posible transacción con los artículos que recomienda" (Schiffman y Kanuk, 2005: 297) es lo que hace que el WOM sea considerado la fuente más influyente para la decisión de compra (Nielsen, 2009a).

En el caso del WOM, se atribuye credibilidad a un emisor cuando reúne tres rasgos: indepen- 
dencia (Arndt, 1967; Schiffman y Kanuck, 2005), pericia o conocimiento (Bansal y Voyer, 2000; Brown et al, 2007; Price y Feick, 1984; Sternthal et al, 1978) y familiaridad (Schiffman y Kanuck, 2005). Cuando se percibe que el emisor tiene una alta pericia, el receptor presta más atención al WOM e incluso tiene más motivación para buscar la información de esta persona (Bansal y Voyer, 2000). Una variable clave para establecer la credibilidad es la motivación. Si se percibe que el emisor está obteniendo una ventaja personal, esto es, si se percibe comprometida su independencia, el WOM será poco eficaz, porque será "descontado" o tenido por no válido (Lazniack et al, 2001). La familiaridad está relacionada con los vínculos fuertes y la similitud, por lo que es de aplicación lo visto más arriba.

En el caso del WOM online, se plantea la hipótesis de la dificultad de evaluar la credibilidad del emisor, ya que no se conoce. Brown et al (2007), en un estudio a través de entrevistas en profundidad con 30 participantes y un análisis de una comunidad online, encontraron que para los receptores hacían un esfuerzo para evaluar a los individuos que facilitaban las recomendaciones. Los receptores buscaban las opiniones de los usuarios que consideraban expertos, según su nivel de conocimiento mostrado en la página. Además, los consumidores hicieron una evaluación de la credibilidad, no sólo de los individuos, sino también de la página web donde la información estaba colgada. Esto demuestra, una vez más, la importancia de la página web como fuente de información.

Otro ejemplo es una investigación sobre los comentarios online de hoteles y las experiencias allí vividas, encontrándose que la presencia de información personal que permitiese identificar a la persona online tenía un efecto positivo en la credibilidad percibida de sus comentarios, lo que, a su vez, resultó en una influencia significativa en la intención del receptor a la hora de reservar un hotel (Xie et al, 2011).

Finalmente, algunos estudios hacen pensar que otros factores podrían moderar la influencia de la credibilidad en la eficacia del WOM. Awad y Ragowsky (2008) por ejemplo, examinaron la influencia del género en la credibilidad y encontraron que para las mujeres la credibilidad en el emisor tenía más peso que para los hombres.

\subsection{La valencia del mensaje}

La valencia del mensaje se refiere al contenido del mensaje, esto es, si el mensaje comunica algo bueno (valencia positiva) o malo (valencia negativa). Los mensajes con una valencia positiva suelen referirse a experiencias agradables (una recomendación sincera hacia un producto o servicio) mientras que los negativos pueden incluir experiencias desagradables (denigración de un producto, rumores y quejas personales). Varias investigaciones han intentado establecer si la valencia afecta el resultado de WOM o no y, si afecta, cuál de los dos tendría más impacto en el proceso de decisión de compra del consumidor.

Varios trabajos han encontrado que el WOM negativo influye en el comportamiento de los consumidores (Dellarocas et al, 2007; Richins, 1983; Van Hoye y Lievens, 2007). Esta influencia se debe a que hay más volumen de WOM negativo, porque se tiende a compartir más las experiencias negativas que las positivas, a que se genera una mayor dispersión del mensaje y, por tanto, se ve más, y a que se tiende a exponerse más a la información negativa que a la positiva, especialmente en situación de incertidumbre (producto o experiencia nuevos para el receptor). 
Por un lado, cuando el mensaje tiene una valencia negativa, se comunica con mayor intensidad y se produce una mayor dispersión del mensaje). Richins (1983) encontró que más de la mitad de los clientes insatisfechos con su compra o experiencia se dedicaban a la transmisión de WOM negativo; es más, los clientes insatisfechos se quejan hasta tres veces más que los clientes satisfechos. Otros estudios han encontrado similares resultados (Anderson, 1998; Dellarocas et al, 2007; Silverman, 2001; Yang y Mai, 2010).

Resulta lógico pensar que los clientes insatisfechos sienten una mayor presión para avisar a otra gente, ya sean amigos, familia e incluso desconocidos, para que ellos lo eviten y así no le ocurra lo mismo a otra persona, esto es, el emisor tiene una mayor motivación para iniciar el WOM. Otra posible explicación es que los consumidores prestan más atención, y dan más importancia, a la información negativa que a la positiva (Hoyer y MacInnis, 2004); es decir, si se supone que la mayoría de la información que se recibe sobre productos o servicios es positiva, cuando se recibe de forma negativa, que choca, se le presta más atención porque es más prominente. Así, la información se difundiría a una velocidad mucho más alta que la positiva, con una mayor dispersión tanto en términos de volumen como de velocidad.

Esta mayor exposición a la información negativa ocurre especialmente cuando se trata de un nuevo producto o experiencia (Lutz, 1975). Cuando algo es nuevo y existe relativamente poca información sobre el producto o la experiencia, se considera que esta información es aún más importante debido a su escasez. Así el WOM negativo, que lleva a una mayor dispersión del mensaje, es especialmente influyente cuando el producto o la experiencia con el producto sean nuevos para el receptor.

Por otro lado, el WOM positivo influye en el proceso de compra, sea creando una imagen favorable hacia la marca o empresa (Arndt, 1967), sea mejorando la actitud y predisposición hacia la marca (Dichter, 1966). Una encuesta realizada por Trnd (2010) a 31.713 de sus miembros en Alemania encontró que los dos tipos de WOM se extienden de una manera parecida, pero el WOM negativo se transmite a más gente: 7,44 y 8,25 personas respectivamente. Esto muestra que el WOM positivo también llega a tener una difusión e influye en el consumidor a la hora de hablar del tema con otras personas, lo mismo que el negativo, pero que al final, el WOM negativo suele llegar a un mayor número de personas.

Sin embargo los consumidores suelen recordar mucho más el WOM positivo que el negativo (Trnd, 2010). En una pregunta sobre la última recomendación de WOM transmitida, se encontró que un 89\% recordaba las buenas experiencias y que un $7 \%$ las negativas, habiendo una gran diferencia, un 82\%, según la valencia. Los resultados se muestran en el siguiente gráfico. Con todo, no hay datos concluyentes sobre este particular, ya que otros estudios han llegado a otras conclusiones. East et al (2005) preguntaron a los consumidores si el WOM había afectado a la decisión de elegir una marca, en varias categorías (por ejemplo, la compañía de telefonía móvil). Encontraron que el WOM negativo tenía el mismo impacto que el WOM positivo en cuanto a la decisión final.

El problema puede ser que, en los estudios llevados a cabo, sólo se han considerado el WOM como una variable dicotómica (positiva o negativa), y no como un rango o escala. Para corregir este problema, Anderson (1998) plantea un mo- 
delo basado en la utilidad que propone una función con forma de U para explicar esta teoría. Su investigación, basada en los datos de satisfacción de los clientes de 203 empresas, ha encontrado que la gente muy satisfecha y muy insatisfecha se suele involucrar más en el WOM y, en paralelo, transmite más información y la gente le suele prestar aún más atención y probablemente lo recuerde más: el WOM es mayor cuando la satisfacción se mueve hacia algún extremo (Anderson, 1998). Por tanto, la intensidad de la valencia es tan importante como la valencia. Con todo, su estudio demostró que los clientes insatisfechos tienden a hablar más de su experiencia que los satisfechos.

Así, pues, no hay resultados concluyentes sobre la forma de influencia de la valencia. Hay evidencias para sostener que la relación es lineal, en forma de $\mathrm{U}$, obteniéndose la mayor influencia en los extremos de la curva. También es esperable que se produzca mayor volumen de WOM cuando la valencia es negativa, pero mayor recuerdo cuando es positiva.

\section{Aproximación a un modelo de WOM}

Como se decía en la introducción de este artículo el fin último de este trabajo es revisar la literatura para identificar las variables determinantes del proceso de WOM con el fin de generar un modelo gráfico que integre estas variables. Como evidencian los párrafos anteriores, los estudios anteriores han analizado la influencia de una, a lo sumo dos, variables. Para lograr una mejor comprensión del fenómeno hacen falta estudios que examinen la influencia conjunta de varias variables, con el fin de aclarar las relaciones de causalidad entre ellas y entre los determinantes y el resultado. Este modelo gráfico pretende, pues, sentar la base para el desarrollo de futuros estudios sobre el tema.

El modelo gráfico se completa con proposiciones, que expresan las relaciones de causalidad entre variables y que pueden servir de base para la generación de hipótesis. Estas hipótesis tendrán que ser falsadas en futuros estudios.

(Cuadro 3 pág. 21)

P1. La credibilidad del emisor está determinada por la valoración que hace el receptor de la pericia e independencia del emisor y la familiaridad con él.

P2a. La motivación del emisor está asociada a la búsqueda de beneficios psicológicos, especialmente, mejora de la auto-estima y mejora de la estima en el grupo.

P2b. La motivación del receptor está asociada a la búsqueda de beneficios funcionales: reducir la incertidumbre y simplificar la búsqueda de información.

P3. La valoración de la motivación del emisor es usada por el receptor como pieza clave para decidir la credibilidad del mismo.

P4. Cuando el WOM es reactivo, esto es, cuando se produce en respuesta a una pregunta o comentario del receptor, es más eficaz.

P5a. Cuando existe un vínculo fuerte entre emisor y receptor, se tiende a generar mayor volumen de WOM.

P5b. Entre individuos con vínculos fuertes se tiende a generar mayor WOM reactivo.

P5c. Entre individuos con vínculos fuertes, existe una mayor familiaridad, por lo que la credibilidad otorgada al emisor es mayor.

P6a. Cuando el mensaje tiene una valencia negativa, se tiende a generar mayor volumen de WOM (mayor dispersión). 


\section{Cuadro 3. Modelo gráfico de proceso de influencia del WOM}

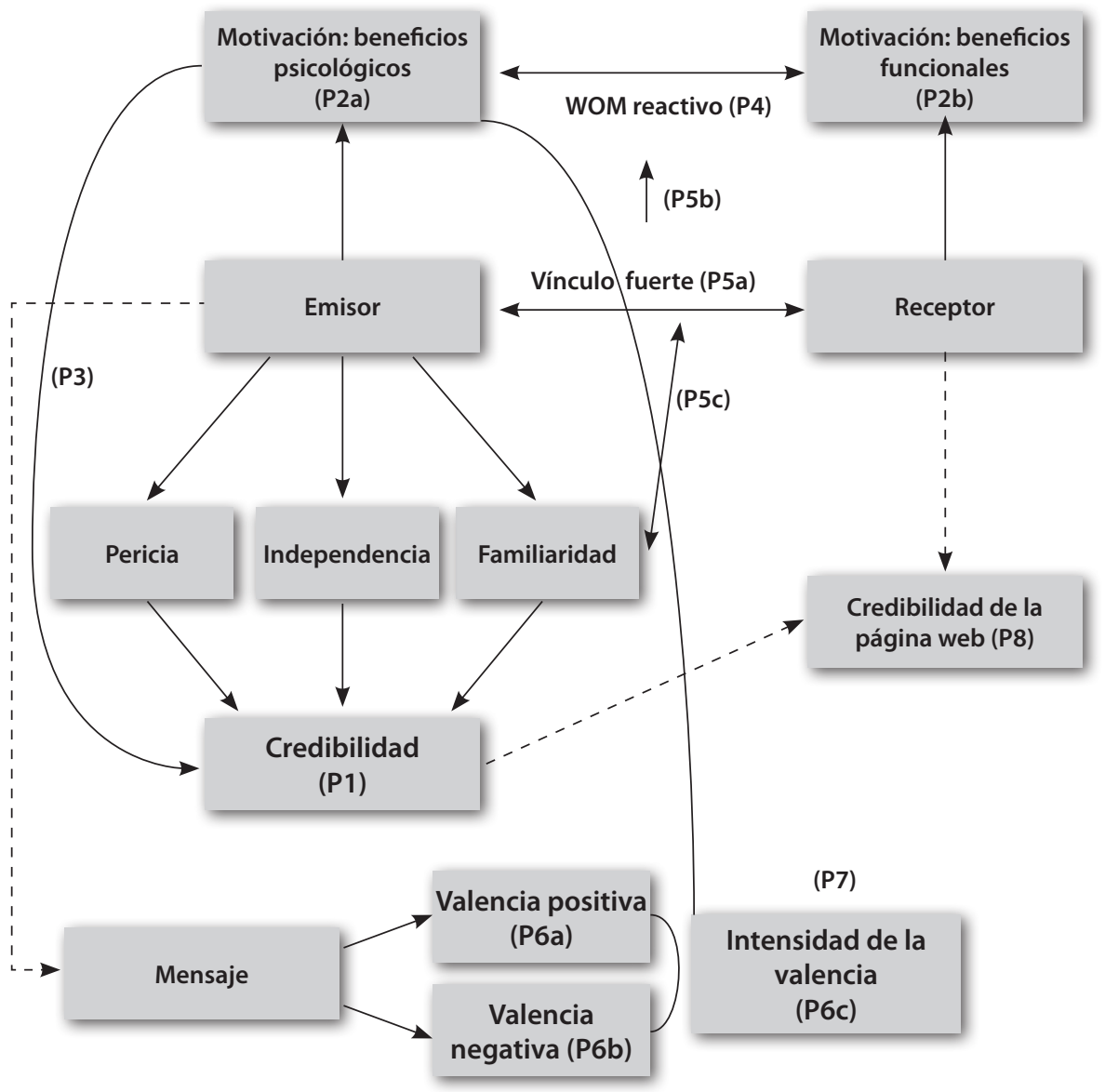

P6b. Cuando el mensaje tiene una valencia positiva, se tiende a generar menor volumen, pero mayor recuerdo del WOM.

P6c. La intensidad de la valencia podría modificar las proposiciones anteriores: a mayor intensidad, mayor dispersión, independiente de si la valencia es positiva o negativa.

P7. La motivación está asociada a la valencia: hay más motivación para iniciar WOM cuando se tiene que comunicar un mensaje con valencia negativa.

P8. En el eWOM, además de la credibilidad del emisor, el receptor juzga también la credibilidad de la página web antes de aceptar el mensaje. Podría haber, pues, una relación entre la credibilidad del emisor y del canal por el que circula el WOM. 


\section{Conclusiones}

La revisión de la literatura efectuada sobre el boca-oreja, o WOM, tanto en su versión analógica como digital, ha llevado a identificar unas variables determinantes clave del proceso. Estas son: la motivación del emisor y receptor, la relación entre los dos, la credibilidad del emisor atribuida por el receptor y la valencia del mensaje. Sin embargo, no se puede concluir de qué manera se produce el impacto o sobre qué variables, ya que la investigación dirigida a medir resultados es limitada; especialmente, los trabajos orientados a ver la influencia del WOM en el proceso de compra.

El valor añadido de este trabajo pasa por recopilar estos estudios en un modelo gráfico y unas proposiciones, que indican la relación de causalidad entre las variables, conectando lo que hasta ahora han sido variables estudiadas de for- ma aislada. Se propone, pues, un modelo en el que se identifican e interconectan las variables que han sido encontradas clave para explicar el proceso de WOM.

Con todo, es necesario desarrollar investigaciones empíricas que permitan falsar las proposiciones generadas. Además, es necesario incorporar otras variables que podrían ser claves, como el tipo de producto o el perfil del receptor, ya que hay estudios que apuntan a que podrían explicar diferencias en el proceso de WOM. Asimismo, es necesario extender la investigación a otros contextos culturales. Actualmente, la investigación está concentrada en países anglosajones, especialmente, Estados Unidos. Es preciso verificar que las variables son las mismas y su influencia se produce en la misma dirección en otros contextos culturales. 


\section{Bibliografía}

AIMC (2010) Navegantes en la Red. Asociación para la Investigación de Medios de Comunicación, Madrid, España. http://www.aimc.es/spip.php?page=rubrique\&id_rubrique $=54$. [fecha de acceso: 4 de enero 2011]

Ajzen, I. y Fishbein, F. (2005). The Influence of Attitudes on Behaviour. En Albarracín, D., Johnson, B., y Zanna, M. The Handbook of Attitudes. (pp. 173-222). New Jersey: Lawrences Erlbaum Associates.

Anderson, E. (1998). Customer satisfaction and Word of mouth. Journal of Service Research. 1(1), 5-17.

Arndt, J. (1967). Role of Product Related Conversations in the Diffusion of a New Product. Journal of Marketing Research. 4(3), 291-295.

Awad, N. y Ragowsky, A. (2008). Establishing Trust in Electronic Commerce Through Online Word of Mouth: An Examination Across Genders. Journal of Management Information Systems, 24(4), 101-121.

Bansal, H. y Voyer, P. (2000). Word of Mouth processes within a service purchase decision context. Journal of Service Research. 3(2), 166-77.

Bickart, B., y Schindler, R. (2001). Internet forums as influential sources of consumer information. Journal of Interactive Marketing. 15(3), 31-40.

Blackwell, R., Miniard, P. y Engel, J. (2002) Comportamiento del Consumidor. México D.F: Thomson. $9^{a}$ edición.

Brown, J. y Reingen, P. (1987). Social Ties and Word-ofMouth Referral Behavior. Journal of Consumer Research, 14(3), 350-362.

Brown, J., Broderick, A. y Lee, N. (2007). Word of mouth communication within online communities: Conceptualizing the online social network. Journal of Interactive Marketing. 21(3), 2-20.

Brown, S. y Beltramini, R. (1989). Consumer Complaining and Word of Mouth Activities: Field Evidence. Advances in Consumer Research, 16(1), 9-16.

Czepial, J. (1974). Word-of-Mouth Processes in the Diffusion of a Major Technological Innovation. Journal of Marketing Research. 11(2), 172-180.

Chintagunta, P., Gopinath, S. y Venkataraman, S. (2010). The Effects of Online User Reviews on Movie Box Office Performance: Accounting for Sequential Rollout and Ag- gregation Across Local Markets. Marketing Science, 29(5), 944-957.

Dellarocas, C., Farag, N., y Zhang, X. (2004). Using Online Ratings as a Proxy of Word-of-Mouth in Motion Picture Revenue Forecasting. Working paper, SSRN Electronic Paper Collection. http://papers.ssrn.com/sol3/papers.cfm?abstract _id=620821. [fecha de acceso: 16 de diciembre 2010].

Dellarocas, C., Zhang, X. y Awad, N. (2007). Exploring the value of online product reviews in forecasting sales: the case of motion pictures. Journal of Interactive Marketing, 21(4), 23-45.

Dichter, E. (1966). How Word of Mouth advertising works. Harvard Business Review, 44(6), 147-166.

Duan, W., Gu, B., y Whinston, A. (2008). The dynamics of online word-of-mouth and product sales - an empirical investigation of the movie industry. Journal of Retailing, 84(2), 233-242.

Duhan, D., Johnson, S., Wilcox, J. y Harrell, G. (1997). Influence on consumer use of word of mouth recommendation sources. Journal of the Academy of Marketing Science. 25(4), 283-295.

East, R., Hammond, K., Lomax, W. y Robinson, H. (2005). What is the Effect of a Recommendation?. Marketing Review. 5(2), 145-157.

Fennis, B. y Stroebe, W. (2010). The Psychology of Advertising. East Sussex: Psychology Press.

Fisher, L. (2008). The Next Big Thing... Buzz Monitoring. Marketing Direct. (Noviembre). p. 10.

Godes, D. y Mayzlin, D. (2004). Using Online Conversations to Study Word-of-Mouth Communication, Marketing Science. 23(4), 545-561.

Granovetter, M. (1973). The Strength of Weak Ties. American Journal of Sociology. 78(6), 1360 -1380.

Gupta, P. y Harris, J. (2010). How e-Wom recommendations influence product consideration and quality of choice: A motivation to process information perspective. Journal of Business Research, 63(9), 1041-1049.

Hennig-Thurau, T., Gwinner, K., Walsh, G. y Gremler, D. (2004). Electronic Word of Mouth via consumer-opinion platforms: what motivates consumers to articulate themsel- 
ves on the internet. Journal of Interactive Marketing, 18(1), 38-52.

Herr, P., Kardes, F, y Kim, J.(1991). Effects of Word-ofMouth and Product-Attribute Information of Persuasion: An Accessibility-Diagnosticity Perspective. Journal of Consumer Research, 17(4), 454-462.

Hoyer, W. y MacInnis, D. (2004). Consumer Behavior. MA: Houghton Mifflin Company. $3^{a}$ edición.

Katz, E. y Lazarsfeld, P. (1955). Personal Influence. Glencoe, IL: The Free Press.

Laczniak, R., DeCarlo, T. y Ramaswami, S. (2001). Consumers' Responses to Negative Word-of-Mouth Communication: An Attribution Theory Perspective. Journal of Consumer Psychology, 11(1), 57-73.

Lam, D. y Mizerski, D. (2005). The Effects of Locus of Control on Word-of-mouth Communication. Journal of Marketing Communications, 11(3), 215-228.

Liu, Y. (2006). Word of Mouth for Movies: Its Dynamics and Impact on Box Office Revenue". Journal of Marketing, 70(3), 74-89.

Lutz, R. (1975). Changing Brand Attitudes through Modification of Cognitive Structure. Journal of Consumer Research, l(4), 49-59.

Martilla, J. (1971). Word of Mouth Communication in the Industrial Adoption Process. Journal of Marketing Research, 8, 173-178.

Mason, R. (2008). Word of mouth as a promotional tool for turbulent markets. Journal of Marketing Communications, 14(3), 207-224.

Myers, J. y Robertson, T. (1972). Dimensions of Opinion Leadership. Journal of Marketing Research, 9(1), 41-46.

Nielsen (2009a). Nielsen Global Online Consumer Survey. The Nielsen Company, New York, USA. http://www. scribd.com/doc/24221838/NIELSEN-Global-OnlineConsumer-Survey-July-2009 [fecha de acceso: 10 de enero 2011]

Nielsen (2009b). Fully-Customizable Brand Monitoring and Analytics Dashboard: My BuzzMetrics. The Nielsen Company.

Norman, A. y Russell, C. (2006). The Pass-Along Effect: Investigating Word-of-Mouth Effects on Online Survey Procedures. Journal of Computer-Mediated Communication, 11(4), 1085-1103.
Price, L. y Feick, L. (1984). The Role of Interpersonal Sources in External Search: An Informational Perspective. Advances in Consumer Research, 11(1), 250-255.

Reingen, P., Foster, B., Brown, J., Johnson, J. y Seidman, S. (1984). Brand congruence in interpersonal relations: A social network analysis. Journal of Consumer Research, 11(4), 771-783.

Richins, M. (1983). Negative Word of Mouth by Dissatisfied Consumers: A Pilot Study. Journal of Marketing, 47(1), 68-73.

Schiffman, L. y Kanuk, L. (2005). Comportamiento del consumidor. México D.F: Pearson Educación. $8^{a}$ edición.

Schindler, R. y Bickart, B. (2005). Published Word of Mouth: Referable, Consumer-Generated Information on the Internet. En Haugtvedt, C., Machleit, J. \& Yalch, R. Online Consumer Psychology: understanding and influencing consumer behaviour in the virtual world. (pp. 35-62), Nueva Jersey: Lawrence Erlbaum Associates.

Silverman, G. (2001). Secrets of Word of Mouth Marketing. Nueva York: AMACOM Books.

Smith, T., Coyle, J., Lightfoot, E. y Scott, A. (2007). Reconsidering Models of Influence: The Relationship between Consumer Social Networks and Word-of-Mouth Effectiveness. Journal of Advertising Research, 47(4), 387-397.

Sternthal, B., Phillips, L. y Dholakia, R. (1978). The Persuasive Effect of Source Credibility: A Situational Analysis. Public Opinion Quarterly, 42(3), 285-315.

Sundaram, D., Mitra, K. y Webster, C. (1998). Word-ofMouth Communications: A Motivational Analysis. Advances in Consumer Research, 25(1), 527-531.

Sweeney, J., Soutar, G. y Mazzarol, T. (2008). Factors influencing word of mouth effectiveness: receiver perspectives. European Journal of Marketing, 42(3/4), 344-364.

Trnd (2010). Estudio sobre el Word-of-Mouth. Informe 01.Barcelona, Madrid. http://company.trnd.com/es/downloads/ trnd_wom_monitor_01.pdf [fecha de acceso: 7 de enero 2011].

Van Hoye, G. y Lievens, F. (2007). Social Influences on Organizational Attractiveness: Investigating If and When Word of Mouth Matters. Journal of Applied Social Psychology, 37(9), 2024-2047.

Xie, H., Miao, L., Kuo, P-J. y Lee, B-Y. (2011). Consumers' responses to ambivalent online hotel reviews: The 
role of perceived source credibility and pre-decisional disposition". International Journal of Hospitality Management, 30(1), 178-183.
Yang, J. y Mai, E. (2010). Experiential goods with network externalities effects: An empirical study of online rating system. Journal of Business Research, 63(9-10), 1050-1057. 